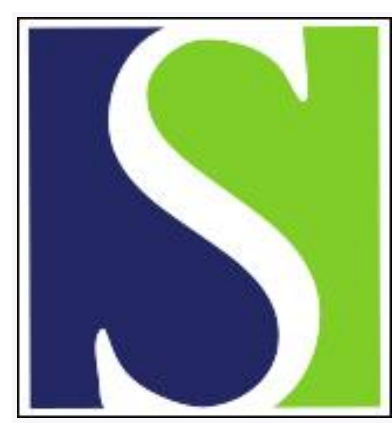

Scand J Work Environ Health 1990;16(6):440-442

https://doi.org/10.5271/sjweh.1762

Issue date: 01 Dec 1990

Association between exposure to a stenching agent in a herbicide packing plant and the occurrence of headache and lethargy.

by Baron $\mathrm{CE}$, Tomenson JA

Affiliation: Occupational Health Department, ICl Chemicals \& Polymers Group, Runcorn, Cheshire, United Kingdom.

This article in PubMed: www.ncbi.nlm.nih.gov/pubmed/2284593

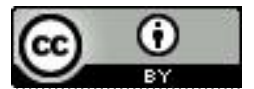




\title{
Association between exposure to a stenching agent in a herbicide packing plant and the occurrence of headache and lethargy
}

\author{
by Charles E Baron, MFOM, ${ }^{1}$ John A Tomenson, $\mathrm{PhD}^{2}$
}

\begin{abstract}
BARON CE, TOMENSON JA. Association between exposure to a stenching agent in a herbicide packing plant and the occurrence of headache and lethargy. Scand J Work Environ Health 1990;16:440-2. This study quantifies the relationship between subjective complaints of symptoms and certain work activities and exposures in a plant where herbicide is packed. Data relating to symptoms were collected from 27 subjects ( 20 men and 7 women) on a daily basis with the use of a questionnaire. In addition, data were collected relating to work activity and exposure to the stenching agent added to the herbicide, atmospheric levels of which were measured with personal monitoring, on a daily basis. Although associations were found between the occurrence of lethargy and certain factors of job history, there was no significant association with exposure to the stenching agent as measured by personal monitoring during the study.
\end{abstract}

Key terms: exposure-response, fatigue, monitoring, subjective.

The study was undertaken in response to complaints of symptoms including headache and lethargy from personnel working in a plant where a herbicide is formulated and packed. A preliminary investigation into the reported symptoms revealed that there had been specific cases of the occurrence of the symptoms of headache, lethargy, and nausea associated with spillages of the fully formulated product. A review of the toxicology, known properties, and likely exposure of all chemicals in use in the plant identified the stenching agent as the only credible chemical cause of the symptoms reported.

The stenching agent by definition and purpose has an unpleasant smell, and the employees who had suffered from headache, nausea, and lethargy had often associated these symptoms with the smell. The stenching agent is a mixture of alkyl pyridines, primarily dimethylpyridine with some ethylpyridine and some trimethylpyridine. There are insufficient data to calculate a median lethal concentration $\left(\mathrm{LC}_{50}\right)$ for the inhalation of any of the main components. The $\mathrm{LC}_{50}$ (for rat) for 2,4-dimethylpyridine lies between 650 and $4300 \mathrm{ppm}(2.0 \mathrm{~h})$. The lowest concentration of any of the other main components found to cause $100 \%$ mortality was inhalation of $2500 \mathrm{ppm}(2.0 \mathrm{~h})$. Acutely high concentrations of pyridine vapor cause irritation to the eyes and mucus membranes in man and can result in headache, giddiness, and nausea, possibly leading to unconsciousness (1).

1 Occupational Health Department, ICI Chemicals \& Polymers Group, Runcorn, Cheshire, United Kingdom.

2 ICI Epidemiology Unit, Alderley Park, Nr Macclesfield, Cheshire, United Kingdom.

Reprint requests to: Dr JA Tomenson, ICI Epidemiology Unit, Alderley Park, Nr Macclesfield, Cheshire SK10 4TJ, United Kingdom.
The main objective of the study was to estimate the risk of symptoms occurring in association with exposure to the stenching agent and to investigate any other possible causes of work-related symptoms.

\section{Materials, subjects and methods}

Subjective symptoms of a general nature such as headache and fatigue have been shown to be common among working groups and may be related to many factors, such as age, gender, physical activity, stress, boredom, type of job, and number of days since last day off (2-4). In view of this fact, we felt it appropriate to study the occurrence of these symptoms in relation to quantitative measures of exposure to the stenching agent.

The investigation of this type of symptom in this work force did not permit the use of a suitable reference group. As an alternative, analysis of the doseresponse relationships was used to identify any possible bias. The study involved 27 subjects $(20$ men and 7 women) who comprised the total work force of the plant and thus included the workers who had originally complained of headache or lethargy. Fourteen study days were identified during a three-week period. The total number of person-days included in the study was 294, of which 72 were not workdays.

In addition to personal monitoring for the stenching agent, each subject was also monitored for noise and temperature when practically possible. At the end of each study day each individual at work had a work activity questionnaire completed for him by his line supervisor. The work activity questionnaire included a record of the job station for that day, the grade of product being handled, and any spillages or unusual incidents which may have given rise to unusual ex- 
posure. Results from personal stench monitors were entered into the work activity questionnaire. The timeweighted averages for the shifts are summarized for the entire study period in table 1 . Approximately $80 \%$ of the results were measured at or below $0.1 \mathrm{ppm}$ and over $98 \%$ were at or below $1 \mathrm{ppm}$.

On the morning following the study day, the subjects attended the medical center and completed a questionnaire regarding the occurrence of symptoms during the previous $24 \mathrm{~h}$. In each case the questionnaire was administered by the same person (the nursing officer).

The relationship between the reported symptoms of lethargy and headache and exposure to the stenching agent was assessed with logistic regression methods. Associations between symptoms and variables measuring work activity were assessed with a subjectadjusted Pearson chi-square test, the Cochran-MantelHaenszel statistic. Seven features of the job histories were examined for an association with symptoms of lethargy or headache. These comprised noise, temperature, exposure to the stenching agent, working with two grades of product (6917C and 7452), and working in two areas (bottle filling shed and the old drum shed). All statistical analyses were performed with the SAS (statistical analysis system) package (5).

\section{Results}

The logistic regression analyses of the relationships between the symptoms and exposure to the stenching agent showed no significant associations. Indeed the relationship between lethargy and exposure almost achieved statistical significance in a negative direction. This result was confirmed when the exposure levels were split into detectable and less than detectable levels and analyzed with the Cochran-Mantel-Haenszel statistic. Personal monitoring devices could detect stenching agent down to $0.1 \mathrm{ppm}$.

Nevertheless there were significant differences in the symptom of lethargy between days spent at work and off work. (Workers were nine times more likely to report symptoms on workdays.) There was a suggestion of a difference in the symptom of headache between days spent at work and off work, but the association was not significant $(\mathrm{P}=0.07)$.

For the female workers none of the seven factors of job history showed a significant association with the symptom of lethargy. In the male group there was a significant association between the symptom of lethargy and work in the bottle filling shed $(\mathrm{P}<0.05)$. There was a positive association between lethargy and work with one particular product grade, but it did not reach statistical significance.

There were no significant associations between any of the work activities and the headache symptoms.
Table 1. Results of the personal atmospheric monitoring for the stenching agent.

\begin{tabular}{lrr}
\hline \multirow{2}{*}{$\begin{array}{l}\text { Shift time-weighted } \\
\text { average (ppm) }\end{array}$} & \multicolumn{2}{c}{ Results } \\
\cline { 2 - 3 } & $\mathrm{N}$ & $\%$ \\
\hline $0.1^{\mathrm{a}}$ & 100 & 40.7 \\
0.1 & 96 & 39.0 \\
$0.2-0.5$ & 41 & 16.7 \\
$0.6-1.0$ & 5 & 2.0 \\
$>1.0^{\mathrm{b}}$ & 4 & 1.6 \\
\hline
\end{tabular}

a Limit of detectability $=0.1 \mathrm{ppm}$.

b Maximum result $=33.6 \mathrm{ppm}$.

\section{Discussion}

The study was carried out as a result of employees' complaints of symptoms related to the smell of a stenching agent. Unfortunately it was not possible to conduct the study on a different work group which was exposed to the same substances and which worked under the same conditions. However, the lack of a relationship between the symptoms and exposure to the stenching agent is a valid and significant finding, as any bias would be expected to operate in a positive direction. As the workers had a preconception about the relationship between the symptoms and the stenching agent, one might expect more symptoms to be reported when the stenching agent was noticeable in the plant. This was not true for headache, and in fact the reverse was found in the case of lethargy.

It is difficult to account for the actual cause of the increased estimated risk of lethargy found to be associated with work. Without a comparison group one cannot conclude that this increase was caused by any factor specific to the job. It is possible that lethargy could be caused simply by the work itself.

An investigation of other possible causes of workrelated symptoms uncovered only one significant association (work in the bottle filling shed). This finding was thought to be artifactual, and indeed more associations might have been expected due to the nature of the possible subjective bias.

In conclusion, there was no evidence that symptoms occur in relation to exposure to the stenching agent in the range of exposures encountered during the study period. From past experience it is accepted that overexposure to the stenching agent, as a result of spillages, may give rise to symptoms, but these should not occur if exposure is controlled within the range found in this study.

\section{References}

1. Reinhardt CF, Britelli MR. Heterocyclic and miscellaneous nitrogen compounds. In: Clayton GD, Clayton FE, ed. Patty's industrial hygiene and toxicology; vol $2 \mathrm{~A}$. New York, NY: John Wiley, 1981:2671-822.

2. Chen MK. The epidemiology of self-perceived fatigue among adults. Prev Med 1986;15(1):74-81.

3. Taylor PJ, Pocock SJ, Hall SA, Waters WE. Headache 
and migraine in colour retouchers. $\mathrm{Br} \mathrm{J}$ Ind Med 1970; 27:364-7.

4. Waters WE. The epidemiology of headaches. Semin Neurol $1982 ; 2(1): 1-8$.
5. SAS Institute Inc. SAS user's guide: version 5 edition. Cary, NC: SAS Institute INc, 1985.

Received for publication: 2 October 1989 